\title{
ПРИНЦИПЫ ВЫБОРА УЧАСТКОВ ЗЕМНОЙ КОРЫ ДЛЯ РАЗМЕЩЕНИЯ ЕКОЛОГИЧЕСКИ ОПАСНЫХ ОТХОДОВ ПРОМЫIIЕННОСТИ
}

\author{
МОРОЗОВ В.Н., БУРОВ И.Ю., ТАТАРИНОВ В.Н.
}

Геофизический центр Российской Академии Наук

Молодежная 3, Москва, 117296, Россия

" Aннотация

Рассмотрены вопросы выбора участков земной коры для размещения $u$ захоронения экологически опасных отходов, в том числе радиоактивных отходов высокой степени активности. Представлены экспертные оченки природных факторов, определяющих изолячионные свойства пород и стабильность структурно-тектонических блоков земной коры, а также условия разделения участков на благоприятные и неблагоприятные $c$ точки зрения риска распространения опасных материалов 6 окружаюирю среду. Методический подход позволяет форяализовать первыи этап выбора участков для размещения отходов и использовать при этом разноплановые базы данных о свойствах, строении и прочессах в земной коре.

Степень надежсности изоляции отходов от окружағопей среды при их захоронении обуславливается естественными изоляционными свойствами геологической среды и стабильностью природных факторов, определяющих сохранность этих свойств во времени. Проблема выбора на территории отдельных стран наиболее стабильньх геологических блоков для захоронения в них экологически опасньх отходов, в том числе радноактивных отходов высокой степени активности, включает в себя решение ряда фундаментальньх задач из области наук о Земле, в частности - геологик, геомеханики и информатики и др. Ниже рассмотрены разработанные нами принциты выбора участков земвой коры для размещения в них экологически опасньх отходов промыпленности. Основныле ее положения безусловно можно использовать и для выбора участков для свалок и захоронения обынных отходов.

Во многих работах, посвященных данной проблеме говорится, что на первом этапе необходимы исследования по районированию территории и выделения участков куда при приемлемых транспортных расходах могут быть доставлены отходы. В основе этих работ должен лежать детальный анализ фондовьх геолого-геофизических и картографических материалов. Естественно, без формализации больпого объема накоптенной информации разнопланового характера из разлштных областей знаний исследователю невозможно ее эффективно использовать при принятии решения о степени экологической пригодности того ити иного участка. Несмотря на то, что капественғые геологические характеристики являются объективными и прошти апробнрование специалистами, без численньх критериев оценки свойств и стабильности структурно-тектонических блоков и компьютерной технологин, позвопяющей быстро проанализировать большое количество вариантов и выбрать экологидески наименее опасный вариант, невозможно решить поставленную задачу. 
Существующие в настоящее время общие подходы к выбору участков дпя размещения экологически опасныт объектов основаны на рассмотрении блоков земной коры, расположенных в тектонически слабоактивньгх районах, обладаюощих малой проницаемостью, тектонической активностью и сейсмичностью. В качестве критериев оценки используются описательные характеристики массива (геологияеский тип пород, морфология й мощность толши водоупоров, глубнна их залегания, и т. д). При этом в большинстве случаев при выборе регионов для размещения экологически опасньх отходов не учнтывается такое важное свойство геологической среды как неоднородность распределения свойств и протекающих процессов.

Оценку стабильности структурно-тектонических блоков, учитьпая накопленный за рубежом и в стране опыт, целесообразно производить в несколько этапов, используя известный принцип последовательного уменьшения размеров анализируемьх участков коры. Первый этап закпючается в оценке региональнного рейтинга территорики и включает в себя анализ карт, архивного материала и результатов других исследованкй в масштабе 1:1 000000 - 1:10 000000 и районирование по трем категориям:

1. Участки, где размещение отходов приведет к негативным экологическим последствиям и строительство могильника отходов невозможно;

2. Участки, где размещение отходов возможно при вытолнении дополнительғых условий;

3. Участки потенциально пригодные для строительства могильников отходов;

При этом осковополагающим является вопрос о граничньх (критериальньгх) параметрах отнесенхя тех или иных участков в указаныые группы. Многие авторы для ранжирования территорий пользуются экспертнбми оценками, оценивая состояние районов в баллах.

Так, в работе [1] приводится результат анализа специальных карт на основе геоннформашионныт технологий для целей предупреждения чрезвычайньх ситуаций. При построении карты использованы 50 характеристик (синематических слоев). Состояние каждой переменной оценивается по пятибалльной ппкале по отношению к нестабильности. Общая нестабильность определяется как отношение суммы баллов для данной территории к сумме, соответствующей условиям наибольшей нестабильности. Затем, при необходимости, вводится корректирующий коэффициент на основе тестирования по контрольным точкам с испољзованием весовых коэффициентов.

В работе [2], посвященной районированию городской территории по степени устойцивости к динамическому воздействцю, функция неустойчивости сконструирована в виде суммы нелинейньх функций отдельньх факторов:

$$
\Phi\left(\mathrm{x}_{1}, \mathrm{x}_{2}, \ldots, \mathrm{x}_{\mathrm{n}}\right)=\sum_{\mathrm{i}=1}^{\mathrm{n}} \varphi_{\mathrm{i}}\left(\mathrm{x}_{\mathrm{i}}\right)
$$

где $\varphi_{i}\left(\mathrm{x}_{\mathrm{i}}\right)$ нелшнейная функщия вида

$$
\varphi_{\mathrm{i}}\left(\mathrm{x}_{\mathrm{i}}\right)=\begin{array}{cc}
0 \text { дाя } & \mathrm{x} \leq \mathrm{f}_{\mathrm{gn} 1} \\
\mathrm{f}_{1}(\mathrm{x}) \text { для } \mathrm{f}_{\mathrm{gn} 1}<\mathrm{x}<\mathrm{f}_{\mathrm{gn} 2} \\
\mathrm{f}_{2}(\mathrm{x}) \text { дाя } & \mathrm{x} \geq \mathrm{f}_{\mathrm{gn} 2}
\end{array}
$$


Необходимо отметить, что этот подход более объективен, но его главньпй недостаток заклюочется в том, чтง зачастую невозможно установить вид функцик $\varphi_{i}\left(x_{i}\right)$ для факторов $F_{n}$. Суцествуют и другие подходы.

По наптему мнению, на данном этапе исследований, на котором, как уже отмедено, анализируются разноплановые параметры в довольно мелком масптабе, экспертная оценка стабильности геологической среды является наиболее понятной для принятия решения о выборе участков для размещения отходов.

Из массы природньг факторов выбраны те из них, от которьх зависят изоляционные свойства пород, гидрогеологические и тектонжческие процессы и с которьми связана динамика распространения экологияески опаснњ материалов и разрупение горного массива. С другой стороны, их количество ограничено, отсутствием надежного картографнческого материала и большим объемом работ по его переводу в машиночитаемую форму.

Все факторы, определяющие стабильность геологического блока, можно обьеденить в 3 групты:

- факторы, характеризующие внутренние свойства пород;

- факторы, характеризующие внешнее активное воздействие;

- факторы, отределяющие динамику процессов протекағощих.

Предтоложим, что на первом этапе было выбрано для анализа $\{\mathrm{J}\}$ - количество блоков земной коры, являюпихся потенциально притодными для размещения отходов. Число значнмых факторов, характеризукоших изолянионные свойства и стабильность блоков равно $\mathrm{N}$. Кажсдый фактор $\left(\mathrm{F}_{\mathfrak{n}}\right)$ характеризует некоторое свойство, состояние или параметры процесса в конкретном структурном блоке и является статистической характеристикой, которая описъвается гистограммой распределения вероятностей данной случайной велшчины.

Диапазон изменений значений фактора $F_{n}$ разобъем на 3 интервала. Граничные интервальные значения $\left(f_{\mathrm{gn} 1}, f_{\mathrm{gn} 2}\right)$ фактора $F_{\mathrm{n}}$ устанавлитаюотся на основе экспертной оценки и являются критериями отнесения раститанного среднего значения $F_{n}$ сp по

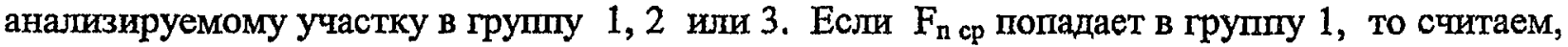
что по данному фактору участок неблагоприятен для размещения отходов, в третью благоприятен, во вторую - участок удовлетворяет требованиям с некоторьми дополтительными условиями. В соответствии с этим фактору $\mathrm{F}_{\mathbf{n}}$ присваивается экспертная оценка равная - 1, 2, 3 баллам.

Влияние каждого фактора неодинаково, поэтому установим весовой козффициент цену фактора $\mathrm{C}_{\mathrm{n}}$, велютину характеризугошую его значимость в интервале от 0 до 1 . Цены факторов безусловно требуют более конкретного обоснования, однако их изменение не может повлиять на относительное значение экспертной оцени.

Определенте граничньх значений $f_{\text {gn } 1}, f_{\text {gn2 }}$ для разделенця факторов по группам вьтолнено на основе сравнения величхн $F_{n}$ в наиболее стабильных участках земной коры (платформы, щиты) с аномальньми зонами (зоны современной тектонической активизации) по картографнческому матержалу, а также путем анализа литературньхх источников, нормативньх материалов и опроса экспертов. Не имея возможности в рамках данной работы подробно отисать весь процесс вьгора критериев экспертной оценки, остановимся коротко на некоторьх общих принципах. 
Наиболее крупной характеристикой земной коры в регшональном плане является тип геодинамической системы литосферы. Отнесение участков земной коры в группы 1,2 и 3 проводилось исходя из следуғощих соображений. Вначале рассматривалась дифференцированность земной коры, связанная с возрастом ее образования; затем морфологический тип геодинамической системы, а также преимущественньй тип геодинамических движений. Уұастки стабилизированной земной коры были оценењы в 3 балла, стабилизирующиеся - в 2 и переходные - в 1 балл. Кроме этого, для участков, имеюгщх морфологический тип с резко выраженной лпнейностьғ, экспертная оценка снижалась на 1 балл. Полигональньй морфологический тип с преобладающими вертикальными перемепениямих был оценен в 3 балла. Уиитьвался также тип геодинамжческих движений - балл снижался для систем, испытывающих растяжение и поднятие, так как растяжение приводит к образованию зон мантийной конвенщии, разломам и т.п., а подннтие - к увеличению скорости эррозии породного массива, с возможными вероятностью выхода могильника на поверхность и изменением гидрогеологического режима.

Интрузнвные породы и соли были отнесены к группе 3, метаморфкческие - к 2, а осадочные к группе 1. В дальнейпем предполагается более подробная дифференциация пород по каждой литологическим разновидностям. Больтую роль играют факторы характеризуюшие изоляционные свойства пород, такие как: плотность региональных разломов, мощность коры выветривания, мощность региональных водоупоров ии петроплотностная характеристика пород. Разделение на групты по плотности региональных разломов было выполнено на основе сравнения участков, обладающих по мнению геологов мощной разломной тектоникой, где заведомо нельзя размещать отходы (плотность разломов более $13 \mathrm{Ha}^{\mathrm{k}} \mathrm{kM}^{2}$ ), и "идеальньх" районов, где плотность разломов составляет величину менее 6 на км². Разделение по плотности горных пород основьвалось на многочисленных натурных определениях плотности для различных литологических разновидностей горных пород, приведенных в стравочниках.

Кроме этого, были уттены такие региональные факторы как плотностная дифференциация мантийно-коровьх блоков, т.е. отклонение плотности от нормы в условных единицах, глубиныые аномалии силы тяжести, глубина залегания поверхности фундамента и мошность консолидированной земной коры. Они косвенно связаны с региональньми зонами разуплотнения и тектонической активностью районов и в меньшей мере определяют изоляпнонные свойства горных пород, что было учтено в уменьшенин их весового коэффициента $-C_{n}$. Разделение на группы проводилось путем сравнения показателей указанных факторов в крайне неблагоприятных районах, например горньй район Тянь-Шаня, и тектонически спокойньгх, напрщмер, щиты Русской платформы.

Во. вторую группу условно бьли отнесены факторы, от которых зависит внешнее воздействие на структурно-тектонические блоки. Это объеденение несколько условно, так как здесь представлено и техногенное воздействие и природное. Гранитные значения сейсмических параметров приняты на оскове карты сейсмического районирования и требований СНиПов, регламентирующих, тто сооружения подобного типа должны выдерживать семибальное землетрясение. Повьпенный уровень естественных напряжений характеризует с одной стороны тектоническую активность района, а с другой связан с образованием повьптенғой естествекной нарушенности породного массива и с 
техногенной нарушенностью, образуемой при проходке подземньх выработок. Из геомеханики известно, что напряжения в массиве выпе 20 МПа уже могут привести к образовавию локальных зон разрупения в зависимости от размеров подземньгх сооружений и типа пород. Поэтому, участки массива, где напряжения превыштағот $20 \mathrm{MМа}$ отнесены к 2 группе, а при превыпении $40 \mathrm{M \Pi а} \mathrm{-} \mathrm{в} \mathrm{первуғо.} \mathrm{Амплитуда} \mathrm{и} \mathrm{градиент}$ скорости вертикалыных движений оценивались на основе экспертного опроса специалистов. Кроме этого к неблагоприятной группе отнесены районы, где плотность населения превьпает 10 чел/км², и имеются крупные охравные объекты (заповедники, аэродромы, АЭС, химические заводы и т.д.).

В третьей группе представлены природные факторы, характеризующие гидрогеологические и тепловые процессы в структурно-тектоническом блоке. Первые ответственны за скорость переноса радионуклидов, в случае возможсного их проникновения за искусственные барьеры, а вторые связаны, согласно кинетическим представлениям о процессах разрушения, со скоростью деструкщии горньх пород. Разделение на групшы проводилось на основе оценки картографического материала. Диапазон максимального изменения зтих характеристик на территория СНГ и условно разбивался на три интервала. Более строгая экспертная оценка этих параметров возможна на основе физического моделирования в подземнъг лабораториях и их характеристики могут быть уточнены.

В табл. 1 представлены: классификация указанньх факторов, диапазон кхх

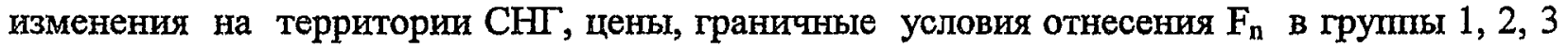
[3].

После распределения каждого фактора по грутпам и присваиванкя им экспертной оценки следующий паг - комплексная оценка суммы всех факторов и принятие ретения о степени пригодности структурных блоков для размещенкя в них экологически опасньх отходов промьшленности. Основой для оценки является предположение о независимости влияния отдельньх факторов друг на друга (действительно, трудно установить зависимость, например, между водопроводимостью и китенсивностью землетрясений). Многхми исследователями, в том числе в работе [2] допускается, что оцениваемые природные факторы независимы друг от друга. В тоже время, авторы видят в этом допущение, вызванное отсутствием в текущей литературе установленных видов зависимостей для большинства факторов, используемых нами.

Для суммарной экспертной оценки состояния структурно-тектонического блока введем понятие рейтинга структурного блока $(\operatorname{Re})$. Рейтинт структурно-тектонических блоков земной коры это сумма произведений экспертных оценок отдельных факторов на их весовые коэффициенты (цены), на основе которого блоки пифференцируются по степени пригодности отдельньх территорий. Он определяется по формуле:

$$
\operatorname{Re}=\sum_{n=1}^{N} F_{n} C_{n},
$$

где $\mathrm{F}_{\mathrm{n}}$ - экспертная оценка фактора в баллах от 1 до $3 ; \mathrm{C}_{\mathrm{n}}$ - цена фактора в относительных единщцах от 0 до $1 ; \mathrm{N}$ - колидество анализируемых факторов.

Для того чтобы определить $\operatorname{Re}$ некоторого района необходимо: 1) Установить некоторое постоянное колнчество анализируемых факторов; 2) Определить диапазон 
измененхя этих факторов в каждой групте; 3) Присвоить каждому фактору цену - $\mathrm{C}_{\mathrm{n}}$ и подсчитать $\operatorname{Re}$ по (1).

Оденить полученную велитину рейтинта можно выбрав два эталонньгх района. Первый (идеализированшый) такой, где все значения факторов попадают в группу 3; второй (нестабильныци), где значения $F_{n}$ ср попадают в группу 1 , (например, район ТяньШаня). Для этих участков определяются рейтинги $\operatorname{Re}_{1}$ и $R_{2}$. Они будут соответствовать максимальному и минимальному значе́нию Re на территории, а рейтинг всех структурнотектонических блоков будет заклюден в интервале от $\operatorname{Re}_{1}$ до $\operatorname{Re}_{2}$. Установив $\operatorname{Re}$ конкретного блока, можно определить приведенный рейтинг - $\mathrm{Re}_{\mathrm{p}}$, характеризующий величину рейтинга в долях относительно "идеапьного" структурного блока.

Тавйица 1

Факторы оценки рейтинга структурно-тектонических блоков земной коры

\begin{tabular}{|c|c|c|c|c|c|c|c|}
\hline \multirow{2}{*}{\begin{tabular}{|l} 
No \\
$\mathrm{n} / \mathrm{\pi}$ \\
\\
1 \\
\end{tabular}} & \multirow{2}{*}{$\begin{array}{l}\text { Название } \\
2 \\
\end{array}$} & \multirow{2}{*}{ 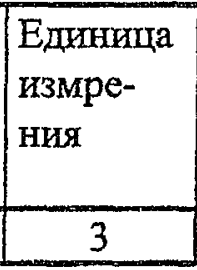 } & \multirow{2}{*}{ 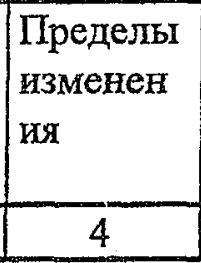 } & \multicolumn{3}{|c|}{ 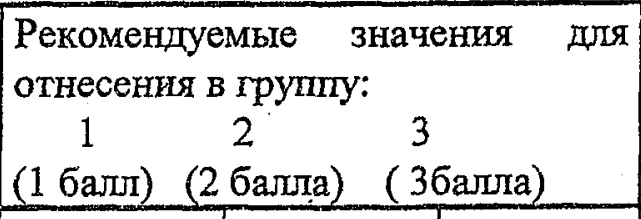 } & \multirow[t]{2}{*}{$\begin{array}{l}\text { Цена } \\
\text { фак- } \\
\text { ropa, } \\
\mathrm{C}_{\mathrm{n}} \\
8 \\
\end{array}$} \\
\hline & & & & 5 & 6 & 7 & \\
\hline \multicolumn{8}{|c|}{ 1.Оценка свойств геолого-структурного блока } \\
\hline 1 & $\begin{array}{l}\text { Геологнческий } \\
\text { пород, тип } \\
\text { основную площадь }\end{array}$ & TuII & $1-3$ & 1 & 2 & 3 & 1,0 \\
\hline $2^{*}$ & \begin{tabular}{|l|} 
Плотность \\
регнональньх \\
разломов \\
\end{tabular} & $1 / \mathrm{KM}^{2}$ & - & $>=13$ & $6-13$ & $<=6$ & 0,6 \\
\hline $3^{*}$ & $\begin{array}{l}\text { Плотностная } \\
\text { дифференциация } \\
\text { мантийно-коровьх } \\
\text { блоков (N-норма) } \\
\end{array}$ & усл.ед & $\begin{array}{l}\mathrm{N}-2 \mathrm{E} \\
\mathrm{N}+2 \mathrm{E}\end{array}$ & $<\mathrm{N}-1,5 \mathrm{E}$ & $\begin{array}{l}\text { N-E-N- } \\
1,5 E\end{array}$ & $>\mathrm{N}-\mathrm{E}$ & 0,3 \\
\hline 4 & $\begin{array}{l}\text { Мошность } \\
\text { региональньг } \\
\text { водоупоров }\end{array}$ & M & $0-2000$ & $<=50$ & $50-100$ & $>=100$ & 0,5 \\
\hline $5^{*}$ & $\begin{array}{l}\text { Моцность } \\
\text { консопидированной } \\
\text { земной коры } \\
\end{array}$ & $\mathrm{KM}$ & $10-50$ & $<=25$ & $25-42$ & $>=42$ & 0,3 \\
\hline 6 & $\begin{array}{l}\text { Геодинамическая } \\
\text { система }\end{array}$ & THII & $1-3$ & 1 & 2 & 3 & 0,5 \\
\hline 7 & $\begin{array}{ll}\text { Мошность } & \text { коры } \\
\text { выпетривания }\end{array}$ & $M$ & $0-300$ & $>=100$ & $50-100$ & $<=50$ & 0,5 \\
\hline $8^{*}$ & $\begin{array}{l}\text { Глубина залегания } \\
\text { поверхности } \\
\text { фундамента }\end{array}$ & KM & $0-(-10)$ & $<=(-3)$ & $(-1)-(-3)$ & $>=(-1)$ & 0,3 \\
\hline $9^{*}$ & Глубинныте аномални & мГал & $(-100)-$ & $z=100$ & $50-100$ & $(-100)-50$ & 0,3 \\
\hline
\end{tabular}




\begin{tabular}{|l|l|l|l|l|l|l|l|}
\hline & силы тяжести & & 150 & & & & \\
\hline $10^{*}$ & $\begin{array}{l}\text { Глубина поверхности } \\
\text { Мохо }\end{array}$ & $\begin{array}{l}(-20)- \\
(-70)\end{array}$ & $>=(-35)$ & $(-35)-(-40)$ & $<=(-40)$ & 0,2 \\
\hline $11^{*}$ & $\begin{array}{l}\text { Петроплотностная } \\
\text { характеристика пород }\end{array}$ & $\mathrm{r} / \mathrm{cm}^{3}$ & $1,9-3,0$ & $<=2,25$ & $2,25-2,70$ & $>=2,70$ & 0,4 \\
\hline $12^{*}$ & $\begin{array}{l}\text { Средняя высота над } \\
\text { уровнем моря }\end{array}$ & $\mathrm{M}$ & $0-8000$ & $>=2500$ & $\begin{array}{l}0-100, \\
1600-2500\end{array}$ & $100-1600$ & 0,4 \\
\hline
\end{tabular}

\section{2.Оценка внешнего воздействия на блок}

\begin{tabular}{|c|c|c|c|c|c|c|c|}
\hline 13 & $\begin{array}{l}\text { Интенсивность } \\
\text { вероятньх } \\
\text { землетрясенй }\end{array}$ & $\begin{array}{l}\text { балты } \\
\text { (шкала } \\
\text { MSK-64) } \\
\end{array}$ & $0-9$ & $>=7$ & $5-7$ & $<=5$ & 0,4 \\
\hline 14 & $\begin{array}{l}\text { Повторяемость } \\
\text { землетрясений }\end{array}$ & $\begin{array}{l}\text { pa3/100 } \\
\text { Jeт }\end{array}$ & $>0$ & $>=1$ & $1-0,01$ & $<=0,01$ & 0,3 \\
\hline $15^{*}$ & $\begin{array}{l}\text { Амплитуда } \\
\text { вертикальных } \\
\text { неотектонических } \\
\text { движений } \\
\end{array}$ & $M$ & $\begin{array}{l}(-7000)- \\
7000\end{array}$ & $>5000$ & $\begin{array}{l}(-500)-0 \\
500-5000\end{array}$ & $0-500$ & 0,5 \\
\hline $16^{*}$ & $\begin{array}{l}\text { Градиент скорости } \\
\text { вертикальньх } \\
\text { неотектонических } \\
\text { движенйй }\end{array}$ & $\begin{array}{l}10 \mathrm{MM} / \mathrm{MM} \\
\text { год }\end{array}$ & $\begin{array}{l}(-2000) \\
800\end{array}$ & $>=1500$ & $\begin{array}{l}800-1500 \\
<(200)\end{array}$ & $\begin{array}{l}(-200)- \\
800\end{array}$ & 0,4 \\
\hline 17 & $\begin{array}{l}\text { Уровень } \\
\text { естествениньх } \\
\text { напряжений } \\
\end{array}$ & MIIa & $0-70$ & $>=40$ & $20-40$ & $\Leftrightarrow=20$ & 0,5 \\
\hline 18 & Плотность населения & qел/ $/ \mathrm{KM}^{2}$ & $0-150$ & $>=10$ & $1-10$ & $<=1$ & 0,4 \\
\hline 19 & $\begin{array}{l}\text { Наличие охраннтьх } \\
\text { объектов }\end{array}$ & да,нет & - & дa & да & нет & 0,2 \\
\hline 20 & Количество осадков & $\mathrm{MM} / \mathrm{M}^{2}$ & $0->2000$ & $>=800$ & $500-800$ & $0-500$ & 0,2 \\
\hline
\end{tabular}

\section{3.Оценка процессов в блоке}

\begin{tabular}{|l|l|l|l|l|l|l|l|}
\hline 21 & $\begin{array}{l}\text { Средний годовой } \\
\text { подземньй сток }\end{array}$ & $0-200$ & $>=1500$ & $800-1500$ & $<=800$ & 0,3 \\
\hline 22 & $\begin{array}{l}\text { Среднемноголетняяве } \\
\text { личияа подземного } \\
\text { стока }\end{array}$ & $0-60$ & $>=50$ & $40-50$ & $<=40$ & 0,3 \\
\hline 23 & Водопроводкмость & $\begin{array}{l}(1 \mathrm{kM} \\
\mathrm{M}) / \mathrm{cyT}^{\circ}\end{array}$ & $0-1500$ & $>=1000$ & $200-1000$ & $<=200$ & 0,5 \\
\hline 24 & Среднтй годовой $\mathrm{\pi} /\left(\mathrm{c} \mathrm{kм}^{2}\right)$ & $0-35$ & $>=25$ & $20-25$ & $<=20$ & 0,4 \\
\hline
\end{tabular}




\begin{tabular}{|c|c|c|c|c|c|c|c|}
\hline & $\begin{array}{l}\text { поверхностный сток } \\
\text { peк }\end{array}$ & & & & & & \\
\hline 25 & $\begin{array}{l}\text { Максимальныц̆ } \\
\text { модуль } \\
\text { стока }\end{array}$ & $\mathrm{M}^{3} /\left(\mathrm{C} \mathrm{KM}{ }^{2}\right)$ & $0-3,5$ & $<=2,5$ & $2,0-2,5$ & $<=2,0$ & 0,2 \\
\hline $26^{*}$ & $\begin{array}{l}\text { Геотермический } \\
\text { градиент }\end{array}$ & $\begin{array}{c}\mathrm{C}^{0} / 1000 \mathrm{M} \\
.\end{array}$ & $5-70$ & $<=50$ & $30-50$ & $<=30$ & 0,2 \\
\hline $27^{*}$ & Тепповой поток & $\mathrm{BT} / \mathrm{m}^{2}$ & $10-70$ & $>=50$ & $40-50$ & $<=40$ & 0,2 \\
\hline
\end{tabular}

* - параметры для которых использованы оцифрованные карты CHI.

В табл. 2 приведены расчитанные знаенния $R e$ и $\operatorname{Re}_{\mathrm{p}}$ для некоторых территорий

Таблица 2

Значения относительного и приведенного рейтингов территорий СНГ

\begin{tabular}{|l|l|l|l|l|l|}
\hline \multicolumn{1}{|c|}{ Район } & $R e$ & $\operatorname{Re}_{p}$ & Район & $R e$ & $R e_{p}$ \\
\hline 1. Идеализированньй & 29,5 & 1,0 & 5. Район Хабаровска & 20,7 & 0,70 \\
\hline 2. Район Москвы & 21,6 & 0,73 & 6. Район Тянь-Шаня & 10,1 & 0,41 \\
\hline 3. Район Красноярска & 25,5 & 0,86 & 7. Район Сев. Кавказа & 15,0 & 0,51 \\
\hline 4. Район Челябинска & 22,4 & 0,76 & & & \\
\hline
\end{tabular}

Из нее следует, что экспертная оценка $R$ е изменяется от 10,1 до 29,5 , a $\operatorname{Re}_{\mathrm{p}}$ or 1,0 до 0,4. Таким образом, появляется возможность районирования территории отдельньхх стран на основе применения геоинформаднонных технологий. Все регионы $\mathrm{CH \Gamma}$ по значениям $\operatorname{Re}$ и $\operatorname{Re}_{\mathrm{p}}$ можно условно разделить на 3 категории:

1. $18,0>\operatorname{Re}>=10,1 \quad 0,61>\operatorname{Re}_{\mathrm{p}}>=0,4$ неблагоприятные районы

2. $24,0>=\operatorname{Re}>=18.0 \quad 0,8>=\operatorname{Re}_{\mathrm{p}}>=0,61$ переходные районы

3. $29,5>=\operatorname{Re}>24,0 \quad 1,0>=\operatorname{Re}_{p}>0,8$ благоприятные районь.

После выбора структурного блока следующий логический таг должен заключаться в оценке ошибки выбора блоков на основе анализа законов распределения случайньхх велктия $F_{n}$ для конкретньх территорий. Это можно сделать на основе известных положений теории статистического анализа вероятностей распределения спучайньх величин [4, 5 и др.]. В общем случае, в каqестве оценки ошибок отрицательного и положкительного рептений по одному фактору $F_{n}$ можно воспользоваться следующим выражением [5],

$$
R_{n}=\left(p_{+n} C_{a n} \alpha_{n}+p_{-n} \cdot C_{B n} \beta_{n}\right)
$$

где $\mathrm{p}_{+\mathrm{n}}, \mathrm{p}_{-\mathrm{n}}-$ вероятности положительной и отрицательной гипотез отнесения фактора $F_{n}$ в группы экспертной оценки $1,2,3 ; \alpha_{n}, \beta_{n}$ - отихбки первого и второго рода, $C_{\text {an }}$, $\mathrm{C}_{\mathrm{gn}}$ - цены оттибок первого и второго рода. 
Для того чтобы обоснованно применить зтот критерий необходимо знать $p_{-n}, p_{+n}$ и $\mathrm{C}_{\mathrm{an}}, \mathrm{C}_{\text {вп, }}$ нахожденте которьх представляет серьезнъге трудности и требует дальнейпих исследований, а также обоснованхя зависимости факторов оценки друг от друга.

Поэтому, ттобы оценить опибку по всем факторам воспользуемся суммарной оценкой величины $R_{n}$, считая эту оценку не строгой в статистическом смысле, а полуколицественной экспертной оценкой отибок выбора блоков. Тогда алгоритм оценки можно представить следующим образом.

1. На основе применения геоннформационных ситсем (ГИС) устанғавливается распределение факторов $F_{1}, F_{2}, \ldots, F_{n}$ в виде гистограмм вероятностей распределения $F_{n}$ в pacrpe $200 \times 200 \mathrm{KM} \mathrm{c} \mathrm{окном}<0,5 \mathrm{KM}^{2}$.

2. Допустив, что распределение факторов для групп 1 и 2 по.форме аналогисны $F_{n}$ конктретного района, строятся гистограммы граничных распределений на уровне порогов $\mathrm{fgn}_{1}$ й $\mathrm{fgn}_{2}$.

3. Для каждого фактора подсчитьваются значения ошибок первого $(\alpha)$ и второго родов $(\beta)$.

4. Определяются риски $\left(\mathrm{R}_{\mathfrak{n}}\right)$ экспертной оценки факторов по отдельньп факторам.

5. Проводится экспертная оценка общего суммарного риска (R) структурнотектонического блока по $\mathrm{N}$ факторам.

В заклюqение неоходимо отметить следующее. Используемые нами положения статистического анализа требуют в дальнейттем строгого обоснования и доработки, вместе с тем, уже сегодня супествует объективная необходимость анализа большого объема данных и принятия оперативных репений по выбору участков для размещщения экологически опасных отходов. Поэтому, авторами и сделана попытка разработки представленных методических основ для прогнозной экспертной оценки состояния участков земной коры при проектировании размещения в них отходов промьппленности с нағменьтим риском загрязнения окружающей среды.

\section{ЛИ T E P A T Y P A}

1. Борунов А.К., Пузаченко Ю.Г., Сорокин А.Д. и др. Картографическая основа геоинформационной системы предупреждения чрезвычайных ситуаций //Изв. РАН. Сер. reorpaф., 1993, N5. C.90-97

2. Лихачева Э.А., Гитис В.Г. и др. Комплексное районирование город-ской территории по степени устойчивости к динамическому воздействию //Теоморфология. 1993. N4. C.41-47

3. Морозов B.Н., Татаринов В.Н. Методика выбора участков земной коры для размещения экологически опасных отходов. Геоэкология. М. 1996. №6 . С.109-120

4. Morozov V.N.,Tatarinov V.N. Formalizing regional kartographical information in designung ecologicaly dangerous installations in the earth's crust. 1st European Congress of Regional Geological Cartography and Information Systems. Italy, Bologna, 1994.

5. Никитин А.А. Статистические методы выделения геофизидеских аномалий. М., Недра, 1979. 280c 